\title{
UMA ANÁLISE DA ACESSIBILIDADE PARA DEFICIENTES VISUAIS NA SEÇÃo BRAILLE DA BIBLIOTECA CENTRAL DA UFPB
}

\section{AN ANALYSIS OF ACCESSIBILITY FOR THE VISUALLY IMPAIRED IN THE BRAILLE SECTION OF THE UFPB CENTRAL LIBRARY}

\author{
Maricélia Matias Costa \\ Bacharel em Biblioteconomia \\ mariceliamatiascosta@hotmail.com \\ Maria Amélia Teixeira da Silva \\ Mestre em Ciência da Informação \\ Professora do Departamento de Ciência da Informação da UFPB \\ melteixeiraufpb@gmail.com
}

\begin{abstract}
Resumo: Na pesquisa foram analisadas as necessidades informacionais dos usuários com deficiência visual total da Seção Braille da Universidade Federal da Paraíba. Para tanto, buscou identificar as necessidades dos usuários nessa seção; descrever as barreiras informacionais existentes sob a perspectiva dos usuários; apontar soluções para que essas barreiras sejam desarticuladas satisfazendo as necessidades de informação dos usuários da Seção Braille. Trata-se de uma pesquisa exploratória e descritiva, com abordagem quanti-qualitativa, na qual um formulário foi utilizado para coleta de dados, cuja aplicação em virtude da deficiência dos respondentes, foi preenchido pela própria pesquisadora que interagiu com eles. Após a análise dos dados foi possível concluir que, no que concerne à acessibilidade, a Biblioteca Central e a Seção Braille da UFPB não possuíam até o momento da pesquisa, uma proposta estruturada de serviços que atendam à demanda atual da Universidade. Sugere-se, desse modo, a adequação do ambiente para atender às demandas futuras de estudantes com deficiência visual, utilizando-se para isso a ABNT NBR 9050.
\end{abstract}

Palavras-chave: Acessibilidade - Biblioteca. Deficiente Visual. Biblioteca Universitária - UFPB.

Abstract: The research analyzed the informational needs of users with total visual impairment of the Braille Section of the Federal University of Paraiba. To this end, it sought to identify the users' needs; describe existing information barriers from the perspective of Braille Section users; to point out solutions for these barriers to be broken down by meeting the users' information needs. This is an exploratory and descriptive research, with a quantitative and qualitative approach, in which a form was used for data collection, whose application due to the deficiency of respondents, was completed by the researcher who interacted with them. After analyzing the data it was possible to conclude that regarding accessibility, the Central Library and the Braille Section of the UFPB did not have, until the moment of the research, a structured proposal of services that meet the current demand of the University. Thus, it is suggested the adequacy of the environment to meet the future demands of students with visual impairment, using ABNT NBR 9050.

Keywords: Accessibility. Visually Impaired. University Library. UFPB.

\section{INTRODUÇÃO}

Os estudos de usuários são investigações centradas no sistema, indivíduo, grupo ou comunidade favorecido com os serviços oferecidos por unidades de informação. De acordo com Moraes (1994), tais investigações objetivam: determinar os documentos requeridos pelos usuários; descobrir os hábitos dos usuários para a obtenção da informação, bem como as maneiras de busca; estudar o uso feito dos documentos; e estudar a maneira de obtenção do acesso aos documentos.

Atentando-se ao acesso e uso da informação como fatores primordiais para o estabelecimento de uma sociedade inclusiva, pressupõe-se determinar nesse contexto o papel das relações entre a universidade e a sociedade para a compreensão dessas problemáticas. As universidades devem analisar 
esses processos limitativos, tanto para a pesquisa como para a formação profissional, com responsabilidade ampla de caráter social, com o objetivo de obter resultados que contribuam para o progresso científico e que contemplem a orientação para o contexto da aplicação, ou seja, para a prática em campo social (BERNHEIM; CHAUÍ, 2008).

Perante essa perspectiva, pode-se considerar a importância da informação para a vida e desenvolvimento do ser humano em toda a sua plenitude. Ponderando-se a respeito das necessidades informacionais da pessoa com deficiência visual, observa-se a questão do acesso à informação e os principais meios que são utilizados por essas pessoas, para a sua obtenção, salientando-se, em conformidade com Malheiros (2009), que o acesso à informação é essencial para a pessoa com deficiência visual, por ser um de seus maiores desafios de formação educacional e inclusão social.

Diante desse contexto, as bibliotecas possuem um importante papel no que diz respeito à inclusão social dos indivíduos com deficiência. Estes são considerados usuários especiais e por isso devem ser alvo de políticas específicas, capazes de lhes possibilitar o acesso à informação, garantindolhes, assim, meios de ascenderem à condição de verdadeiros cidadãos, capazes de desenvolver a capacidade crítica e reflexiva necessária para lutarem por seus direitos e também participarem como sujeitos dos processos de transformação da sociedade (PINHO NETO, 2013).

A Constituição Federal (CF) de 1988 é o ponto de partida de destaque aos direitos às pessoas com deficiência, e ao compromisso da universidade com o direito à educação, à acessibilidade e à inclusão. Não se pode perder de vista que a universidade deve desempenhar um papel democratizador junto à sociedade e colocar-se contra a exclusão social e a privatização dos conhecimentos, como bem lembra Chauí (2003).

Nesse sentido, as bibliotecas universitárias, foco central deste estudo, precisam estar alinhadas a esse cenário. Compete às bibliotecas universitárias prover à comunidade acadêmica, incluindo os que apresentam limitação visual, física e surdez, recursos de informação, oferecendo serviços e produtos diferenciados às suas limitações e potencialidades. (PUPO; MELO; FERRES, 2008).

Diante disso, precisam ser garantidas possibilidades de acesso iguais e justas a todos, criandose ambientes que ofereçam recursos tanto em termos de espaço físico, como acervo e capacitação pessoal. As bibliotecas universitárias apresentam-se com o mérito de buscar, por meio de tecnologia de informação, formas alternativas para compartilhar e contribuir no processo de aprendizagem, possibilitando o acesso ao conhecimento e favorecendo a garantia do direito à educação.

A inquietação da pesquisa surgiu após visita à Seção Braille da Biblioteca Central da Universidade Federal da Paraíba. Barreiras relacionadas ao livro em Braille, a falta de equipamentos adequados para áudio-books, barreiras de acessibilidade para chegar á Seção da biblioteca destinada ao usuário com deficiência visual, barreiras de sinalização, falta de higiene do acervo Braille, ausência de atividades de marketing com o objetivo de atrair mais usuários da universidade à Seção, foram alguns dos motivos impulsionadores desta pesquisa. 
Com o objetivo de analisar as necessidades informacionais dos usuários com deficiência visual total da Seção Braille da Biblioteca Central da Universidade Federal da Paraíba, buscou-se questão identificar as necessidades dos usuários da Seção Braille; descrever as barreiras informacionais que da referida Seção e; apontar soluções para que essas barreiras sejam desarticuladas satisfazendo as necessidades de informação do usuário da Seção Braille.

\section{BIBLIOTECA CENTRAL DA UNIVERSIDADE FEDERAL DA PARAÍBA}

O processo de estruturação e implantação da Biblioteca Central, a partir da junção das treze Bibliotecas Departamentais, iniciou-se em 1976, através da contratação de bibliotecários, atualização do acervo, elaboração e aprovação do regulamento do Sistema de Bibliotecas, criação de novos serviços, automação dos serviços técnicos, entre outros, culminando com a construção do prédio definitivo da Biblioteca Central com uma área construída de $8.500 \mathrm{~m}^{2}$ (SILVA, 2004).

No ano de 1977, o Regulamento do Sistema de Bibliotecas da UFPB passou por uma mudança para reformulação e ampliação dos serviços prestados ao público. O Regulamento do Sistema de Bibliotecas foi aprovado pelo CONSEPE em 1980. O mesmo pode ser conhecido como Sistemoteca que tem como órgão central a Biblioteca Central da Universidade Federal da Paraíba e pode ser considerado como:

Um conjunto de bibliotecas integradas sob os aspectos funcional e operacional. Tendo por objetivo a unidade e harmonia das atividades de coleta, tratamento, armazenamento, recuperação e disseminação da informação para o apoio aos programas de ensino, pesquisa e extensão (SINTONIO, DUTRA apud SILVA, 2004, p.5).

A Biblioteca Central é considerada como um dos órgãos suplementares da UFPB. É formada pela Diretoria, Vice-Diretoria, Secretaria Administrativa, Setor de Contabilidade e por três Divisões, que se subdividem em 11 Seções, a saber: Divisão de Desenvolvimento de Coleções (DDC), a Divisão de Processos Técnicos (DPT) e a Divisão de Serviços ao Usuário (DSU) (BRASIL, 2009).

Os recursos financeiros para o Sistema de Bibliotecas da Universidade Federal da Paraíba, que compreende as bibliotecas setoriais e a Biblioteca Central, na forma da legislação vigente, poderão ser oriundos de dotação orçamentária ou rendas próprias. A Biblioteca Central será a única unidade da UFPB que disporá de dotações orçamentárias para aquisição de material documental e assinatura de periódicos, cabendo a mesma, a distribuição entre as Bibliotecas Setoriais, da dotação orçamentária recebida, em função do plano de necessidades de aquisição do material documental, apresentado por cada uma das bibliotecas (BRASIL, 2009).

\subsection{SEÇÃO BRAILLE DA BIBLIOTECA CENTRAL DA UFPB}

Inicialmente, a Seção Braille, localizava-se no térreo do prédio da Biblioteca Central da UFPB, estando subordinado à Seção de Coleções Especiais. Atualmente, localiza-se no primeiro andar do mesmo prédio e está subordinada à Divisão de Serviços aos Usuários (DSU). 
Sua missão é dar apoio aos alunos com deficiência visual disponibilizando um acervo com 3.430 volumes em Braille, periódicos atualizados e um acervo de multimeios com 247 títulos, tudo organizado por ordem alfabética de título na sequência da CDU (Classificação Decimal Universal).

No quesito acessibilidade a Seção precisa de alguns ajustes. A primeira grande barreira seria sua localização no primeiro andar do prédio, pois não existe rampas e o elevador está sem uso. A sinalização Braille está desatualizada e depredada, existe apenas em alguns quadros, não existe piso tátil para orientar o caminho, sendo o piso muito liso com risco de quedas. Os móveis, de modo geral, não são adaptados, as mesas possuem pontas onde frequentemente observa-se que usuários e funcionários se machucam. Possui estantes de ferro inadequadas para o material, devido o avanço da ferrugem e poeira, apagam o Braille impresso nos exemplares. A Seção possui pouca iluminação e algumas fiações encontram-se expostas.

Sua estrutura funcional, à época da pesquisa, possuía quatro funcionários efetivos: Josenildo Costa, atual chefe da Seção, Bibliotecário desde 1997, especialista em Língua Portuguesa, funcionário da Seção desde 2008; Marília Guedes Pereira, Bibliotecária desde 1975, Mestre em Biblioteca Pública, especialista em Automação, funcionária da Seção desde 1990; Paulo da Silva Chagas, Bibliotecário desde 1984, especializado em Língua Portuguesa, funcionário da Seção desde 1985, no cargo de revisor de textos Braille; José Carlos Barbosa da Silva, graduado em Pedagogia e pós-graduado em Psicopedagogia, funcionário da Seção desde 2013, no cargo de Assistente administrativo. Atualmente não conta com estagiários.

Dentre os serviços oferecidos pela Seção estão: empréstimo, renovação e devolução de livros Braille; Empréstimo, renovação e devolução de livros-falados; Empréstimo, renovação e devolução de periódicos; Consulta ao acervo, por meio do catálogo eletrônico e físico; Orientação aos usuários; Digitalização e impressão de materiais em Braille.

\section{ACESSIBILIDADE EM BIBLIOTECAS PARA PESSOAS COM DEFICIENCIA VISUAL}

As necessidades peculiares de uma pessoa com deficiência visual foram delineadas em conformidade com suas condições fisiológicas e educacionais. Para o fator educacional, podem-se apresentar dois tipos de deficiência visual, cegueira e baixa visão, que são determinadas de acordo com as ferramentas que são utilizadas para o seu desenvolvimento no processo de ensino-aprendizagem.

Para as pessoas consideradas cegas que efetuam o processo de aprendizagem por meio dos sentidos remanescentes - tato, audição, olfato e paladar - destaca-se a utilização do sistema Braille que é o principal meio de comunicação de escrita e leitura. O processo educacional para as pessoas com baixa visão se desenvolve, principalmente, por meios visuais, ainda que com o auxílio de recursos específicos.

$\mathrm{Na}$ atualidade as pessoas com baixa visão podem contar com auxílios ópticos como, óculos de diferentes tipos, lupas e telescópios, assim como, usufruir auxílios não ópticos, como caderno com pautas mais grossas, tiposcópio, ampliação de livros, entre outros. 
Esses são considerados alguns dos principais meios de acesso à informação que a pessoa com deficiência visual disponibiliza em seu cotidiano para o aprimoramento intelectual, formacional, informacional e profissional. São adaptações e utilização da tecnologia assistiva que estão facilitando a vida dessas pessoas.

A tecnologia assistiva é definida como qualquer item ou sistema de produtos, que podem ser adquiridos comercialmente ou desenvolvidos de forma artesanal, produzido em série, modificado ou elaborado sob medida, para que possam ser utilizados para aumentar, manter ou melhorar habilidades de pessoas com limitações funcionais (PUPO; BONILHA; CARVALHO, 2004).

É uma tecnologia considerada assistiva por ser utilizada para o auxílio do desempenho funcional de atividades, permitindo a redução de incapacidades para a efetuação de atividades do cotidiano. Essa tecnologia é utilizada por profissionais da área da saúde, reabilitação e educação.

São instrumentos eficazes que podem, e devem ser utilizados para algumas estratégias e como ferramentas para o manuseio em serviços informacionais para permitir o acesso à informação.

A utilização ampla e exclusiva do sistema Braille e da tecnologia assistiva em unidades de informação, caracteriza um tipo de biblioteca que é denominada como bibliotecas especiais, que têm por finalidade atender a um tipo específico de leitor, levando-se em consideração as peculiaridades de sua clientela ou os materiais com que trabalham (OLIVEIRA, 2005).

As chamadas bibliotecas Braille estão inseridas nesse contexto por ser uma biblioteca direcionada para pessoas com deficiência visual e por lidar com materiais específicos de utilização desses usuários. Essas bibliotecas vêm acompanhando a ascensão da economia informacional, que vem ocorrendo desde a década de 1970, o que tem focalizado os aspectos da tecnologia assistiva, trazendo para o usuário com deficiência visual, novas possibilidades e expectativas em termos de estudo, trabalho e lazer (PUPO; BONILHA; CARVALHO, 2004).

\subsection{O USUÁRIO COM DEFICIÊNCIA VISUAL}

O usuário é o elemento fundamental para a unidade de informação e possuem múltiplos papeis devendo ser elaboradas políticas inerentes a cada perfil. Eles são responsáveis por embasar existência, manutenção, atribuição de recursos e pela política da unidade de informação.

O usuário é um agente essencial na concepção, avaliação, enriquecimento, adaptação, estimulo e funcionamento de qualquer unidade de informação. Ele é um fator dinâmico, mas pode ser também um fator de resiliência se desconhece os mecanismos da informação e se retém informação (GUINCHAT; MENOU, 1994, p. 483).

Assim a Seção Braille da Biblioteca Central da Universidade Federal da Paraíba busca mesmo com dificuldades, colocar no centro de suas prioridades o usuário com deficiência visual.

Ainda de acordo com Guinchat e Menou (1994) podemos dividir os usuários da Seção em três grupos principais: estudantes, profissionais e cidadãos. Os estudantes dos mais variados cursos de graduação desta universidade, dividem-se entre o acervo da Seção Braille e os serviços do Núcleo de Educação Especial (NEDESP), localizado no Centro de Educação da mesma Universidade. 
Os usuários profissionais abrangem os funcionários e professores da instituição com deficiência visual. E finalmente os usuários cidadãos referem-se aos que a Seção possuía e hoje são poucos, os quais o acervo era levado até eles, através de um transporte disponibilizado pela direção da Biblioteca para levar livros e usuários. Hoje os livros são emprestados dessa forma a poucos usuários desta categoria, pois o transporte é realizado pelos próprios funcionários da Seção de maneira tímida, pois os exemplares são grandes e pesados.

\subsection{BARREIRAS INFORMACIONAIS X ACESSO A INFORMAÇÃO}

À explosão documental, a globalização e dos avanços tecnológicos, proporcionaram a diminuição da distância entre as pessoas, barreira que causa custos e desperdício de tempo. Para Aquino (2002, p. 206) esta diminuição é devida “[...] as trocas informacionais propiciadas, atualmente, pelas redes digitais [...] fazendo emergir um novo paradigma: a partilha cooperativa do conhecimento". Nesse contexto a informação produzida em tempo real pela sociedade, torna-se cada vez mais um elemento de inclusão social trazendo desenvolvimento para as pessoas.

Para melhor compreendermos esse processo de acesso e a informação, Le Coadic define o que é informação:

É um conhecimento inscrito (registrado) em forma escrita (impressa ou digital), oral ou audiovisual, em um suporte [tendo como] objetivo permanecer sendo a apreensão de sentidos ou seres em uma significação, ou seja, continua sendo o conhecimento; e o meio é a transmissão do suporte, da estrutura. (LE COADIC, 2004, p.04)

Podemos perceber que o conceito de informação é complexo, pois é necessário que haja percepção de sentido e significado, levando em consideração o meio que a informação é vinculada. Em consonância com este pensamento, Oliveira (2005, p.18) enfatiza: “[...] a informação é um objeto complexo, flexível, mutável, de difícil apreensão, sendo que sua importância e relevância estão ligadas ao seu uso [...] e por tradição, se relacionam a documentos impressos e a bibliotecas”. Sendo assim, a importância da informação está referindo-se ao uso e consequentemente ao acesso. Portanto, são nas unidades de informações que ela será disponibilizada adequadamente, uma vez que nessas unidades deve ter profissionais qualificados para auxiliar o usuário na recuperação da informação.

Diante deste contexto, percebe-se que as bibliotecas fazem parte do processo educacional. Ferreira (1980) mostra que seu acervo possibilita ao cidadão a ampliação de seus conhecimentos, pois possuem papel essencial para a democratização do conhecimento. Os indivíduos são motivados a procurar as bibliotecas pela necessidade de informação e vão à busca dela para preencher o vazio da dúvida, do desconhecimento, para firmar-se como cidadão atuante perante a sociedade.

Enfatiza-se que o processo informacional não alcança as expectativas dos usuários na sua totalidade, pois nesse percurso segundo Gerhard et al. (2007) há o que ela denomina de ruído e a biblioteconomia reconhecem como ruídos os obstáculos ou barreiras informacionais. 
Destacaremos três barreiras informacionais que dificultam à recuperação da informação por parte do usuário que segundo Freire (1991) são as barreiras legais, barreiras terminológicas e barreira de eficiência.

As barreiras legais são representadas pelas limitações ao acesso e uso da informação, especificamente a informação tecnológica (aplicável à produção de bens e serviços). Starec (2006) afirma que a tecnologia de informação e de comunicação emergiu para facilitar, porém, algumas vezes, o que observamos é que elas terminam dificultando o dia a dia nas instituições.

A importância da tecnologia da informação está sujeita acima de tudo a informação e a função representada por ela nas organizações. Nosso encantamento pela tecnologia nos faz esquecer o objetivo principal da informação - informar. Não adianta ter tantos computadores, maquinários e equipamentos se os usuários não despertarem o interesse pela informação que eles podem produzir ou mediar, além disso, temos que estar atentos para não cometermos o erro de acreditar que os sistemas de informação estão isento de falhas, a esta realidade podemos atribuir de dependência tecnológica.

A segunda, as barreiras terminológicas, destacam que não é com assiduidade que os usuários e agentes de informação utilizam o mesmo sistema convencional, de símbolos ou de sinais e de regras combinatórias integrado de linguagem no processo de recuperação do conhecimento, podendo suceder, especialmente na transferência da informação para o setor produtivo, que os termos técnicos utilizados tornam difícil à compreensão da mensagem pelos usuários finais.

Bezerra (2003) compartilha do mesmo pensamento, pois segundo ela a barreira terminológica é devido ao exagero de termos ou de uma terminologia instável no recinto das organizações ou de grupos comuns a várias disciplinas podendo causar distorções, rejeições ou interpretações errôneas. Outra vertente desta barreira seria também a inexistência de termos ou de uma terminologia instável.

Para finalizar, as barreiras de eficiência, que influenciam de duas formas: primeiro do ponto de vista do agente que transfere a informação (comunicador), que pode ser reconhecido na relação entre esforço para informar e usos/efeitos da informação; e por fim, do ponto de vista do usuário, na medida dos esforços para levar a efeito o uso dos serviços de informação (custos financeiros, tempo, estratégias de busca e outros esforços), ou seja, a barreira de eficiência atua tanto do ponto de vista do sujeito que transmite a informação, denominado de emissor, como do sujeito que emprega tal informação - o receptor, em termo de combinação de busca, despesas financeiras e outros serviços (BEZERRA, 2003).

Pelo exposto pode ser percebido que as dificuldades no processo de recuperação da informação dar-se-á na comunicação indireta na qual “[...] a mensagem do comunicador não alcança imediatamente o receptor, como ocorre na comunicação pessoal, mas é transformada em outros sinais e transportada por outros meios" (FREIRE, 1991, p.52). Ou seja, a informação do emissor não chega no mesmo momento ao receptor, como ocorre na comunicação pessoal, mas é transformada em outros sinais e transportada por outros meios. 


\subsection{INCLUSÃO SOCIAL}

O direito à cidadania, à igualdade e à dignidade são valores há muito tempo discutidos na história da humanidade. O direito de ir e vir, de trabalhar e de estudar é a mola-mestra da inclusão de qualquer cidadão e, para que se concretize em face das pessoas com deficiência, há que se exigir do Estado à construção de uma sociedade livre, justa e solidária art. $3^{\circ}$, Constituição Federal, (BRASIL, 2009, p. 11). Para o Ministério do Trabalho, no que se refere às pessoas com deficiência, as políticas públicas estão superando a característica assistencialista e excludente para possibilitar uma inclusão efetiva (BRASIL, 2009).

O manifesto contra o Estatuto da Pessoa com Deficiência mostra que muito ainda necessita ser aperfeiçoado, as pessoas com deficiência clamam por participação igualitária em sociedade, com os mesmos direitos e obrigações, incluídas nos serviços oferecidos à população cujas especificidades somente serão necessárias quando as condições de uma determinada deficiência assim exigirem.

A inclusão é um movimento baseado em um sistema de valores que faz com que todos se sintam bem-vindos, celebrando a diversidade - seja esta diversidade de gênero, nacionalidade, raça, linguagem de origem, nível social, educacional ou deficiência, afirma Mitler (2003).

Marques e Marques (2003, p. 247) observam “[...] um deslocamento de sentido na direção da superação desse modelo excludente de sociedade por um novo modelo fundado no reconhecimento e no respeito à diferença."

Em particular, no que dizem respeito à deficiência visual, as Bibliotecas devem se adaptar para acolher seus usuários, mas isso não ocorre, pois esses espaços na maioria das vezes, não apresentam uma arquitetura pensada para esse tipo de uso. Incluir e qualificar, a acessibilidade tem que ser universal, para aproximar as diferenças, para isso abre-se o caminho para o processo de inclusão.

Por sua vez os bibliotecários devem estar conscientes de que o problema maior não é prover informações para o deficiente visual e sim criar condições acessíveis para que o mesmo se interesse e venha utilizar os serviços e produtos oferecidos pelas bibliotecas. Com princípios como estes podemos comprovar que quanto mais ferramentas ofertadas mais incluídos estarão. As atividades dos bibliotecários para com os deficientes visuais, não devem ser constituídas por ações isoladas, devem envolver a participação de outros organismos que lidam com a questão da deficiência visual, visando fortalecer o trabalho entre bibliotecas (SOUZA, 2013).

\section{PROCEDIMENTOS METODOLÓGICOS}

De acordo com Marconi e Lakatos $(2011$, p.1) a pesquisa é "[...] um procedimento formal, com método de pensamento reflexivo, que requer um tratamento reflexivo e se constitui no caminho para se conhecer a realidade" esse caminho refere-se a metodologia da pesquisa.

Essa concepção mostra que na existência de uma pesquisa, torna-se necessário seguir um roteiro organizacional no seu desenvolvimento onde por sua vez Silva (2004) afirma que para que seus resultados sejam satisfatórios se torna necessário que o processo de pesquisa esteja baseado em planejamento cuidadoso, reflexões conceituais sólidas e alicerçados em conhecimentos já existentes. O 
método científico aproveita a observação, a descrição, a comparação, a análise e a síntese, além dos processos mentais da dedução e da indução, comuns para todos os tipos de investigação (CERVO; SILVA; BERVIAN, 2007, p. 29).

A princípio foi realizada uma pesquisa bibliográfica com temas sobre deficiência visual, acessibilidade, inclusão, biblioteca e o usuário com deficiência visual. Esta busca foi construída através da consulta a livros disponíveis na própria Biblioteca Central da UFPB, como também livros e artigos disponíveis na internet por meio de bases de dados confiáveis, a exemplo da SCIELO (Scientific Electronic Library Online) para a construção do referencial teórico.

Do ponto dos seus objetivos a pesquisa caracterizou-se como sendo exploratória e descritiva. De acordo com Gil (2007) a pesquisa exploratória visa proporcionar maior familiaridade com o problema com vistas a torná-lo explícito ou a construir hipóteses. Na pesquisa em questão, buscou-se identificar quais as necessidades informacionais dos usuários com deficiência visual total da Seção Braille da Biblioteca Central da Universidade Federal da Paraíba. Já a pesquisa descritiva segundo Gil (2007, p. 43) "[...] têm como objetivo principal a descrição de determinada população ou fenômeno ou, então, o estabelecimento de relações entre variáveis".

Do ponto de vista dos procedimentos técnicos assumiu a configuração de pesquisa bibliográfica e pesquisa participante. A pesquisa bibliográfica segundo Gil (1991) caracteriza-se pela busca de informações em fontes bibliográficas, seleção de documentos que se relacionam com o problema da pesquisa (livros, artigos de revistas, trabalhos de congressos, teses, dissertações etc.) e a respectiva leitura, análise e reflexão sobre o material selecionado, para que sejam posteriormente utilizados (na identificação do material referenciado ou na bibliografia final). Já a pesquisa participante de acordo com Gil (1991) se desenvolve a partir da interação entre pesquisadores e membros das situações investigadas.

Quanto ao tipo de abordagem é quanti-qualitativa. Identificaram-se traços da pesquisa quantitativa, pois, recorre à linguagem matemática para descrever as causas de um fenômeno, as relações entre variáveis, etc. (GERHARD et al., 2009). Já nos métodos qualitativos, segundo Gerhard et al (2009, p. 32) "Os pesquisadores buscam explicar o porquê das coisas, exprimindo o que convém ser feito". Na pesquisa em questão, essa interação ocorreu por meio da aplicação do formulário com os respondentes, que em virtude da deficiência dos mesmos, foi preenchido pela própria pesquisadora, através do contato direto e presencial.

A Seção Braille da Biblioteca Central da UFPB em parceria com o Comitê de Acessibilidade da UFPB disponibilizaram os contatos de 20 alunos dos mais variados cursos de graduação da UFPB e com todos foi feito contato via e-mail para a aplicação do formulário, contudo apenas 10 participaram da pesquisa, pois alguns dos alunos já haviam concluído sua graduação. O formulário, contendo oito questões semiabertas, foi aplicado no período de 15 a 16 de maio de 2016, com 10 alunos da Universidade Federal da Paraíba, que possuem deficiência visual total. 


\section{APRESENTAÇÃO E DISCUSSÃO DOS RESULTADOS}

Analisaremos cada questão e de acordo com os resultados obtidos serão tecidos alguns comentários. Nas repostas abertas, o usuário será identificado pela letra U seguida de numeração em ordem crescente, correspondente a obtenção de respostas para cada formulário.

Na primeira questão perguntamos se o aluno tem conhecimento da existência de sinalização Braille na Seção e na Biblioteca Central da UFPB. A referida sinalização é demonstrada na figura 1.

Figura 1- Sinalização da Seção Braille

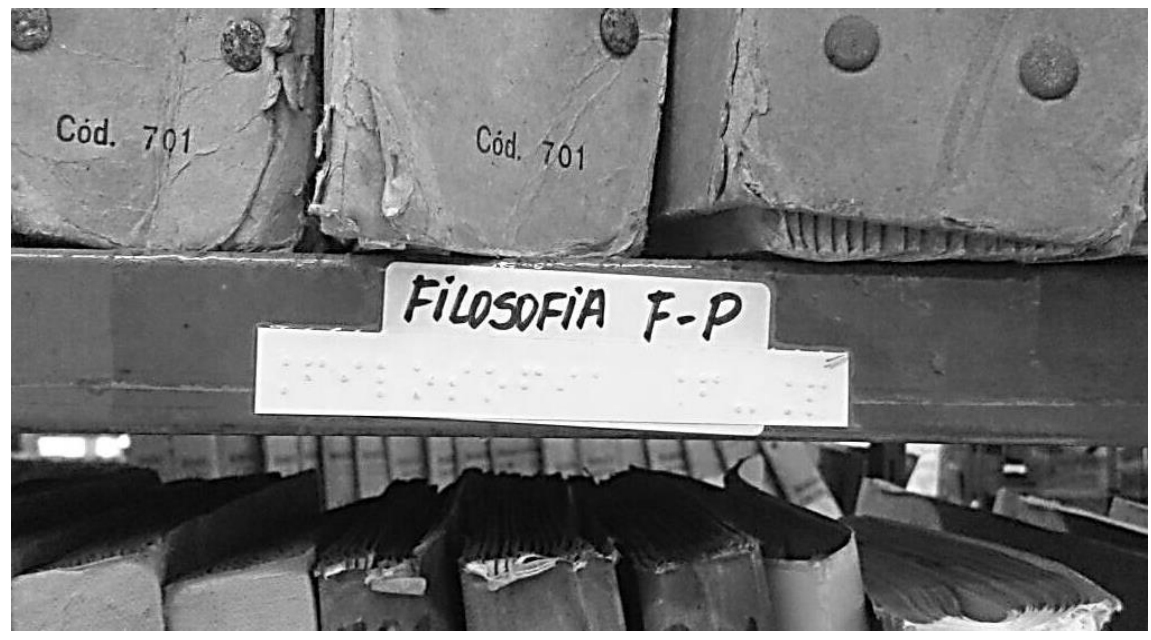

Fonte: Arquivo Pessoal, 2016.

O percentual de $60 \%$ dos usuários informou que não tem conhecimento da existência de sinalização Braille nem na Biblioteca Central da UFPB nem na Seção Braille. Como se observar na imagem acima (FIGURA 1), a etiqueta para o usuário vidente é escrita manualmente e o Braille de algumas destas sinalizações já estão apagados. Foi observado que apenas na Seção Braille existe esse cuidado da sinalização visual e Braille, tendo em vista que as demais Seções e acervos da Biblioteca Central não possuem essa sinalização tátil mesmo que com falhas. Os demais $40 \%$ responderam que não possuíam conhecimento da sinalização.

Para o U7:

"Embora eu possua ciência da sinalização, considero que a mesma não é eficaz".

De início, cumpre frisar que, segundo a norma 9050 da ABNT, existem três formas de comunicação e sinalização, sendo elas: Visual (Realizada através de textos ou figuras); Tátil (Realizada através de caracteres em relevo, Braille ou figuras em relevo) e; Sonora (Realizada através de recursos auditivos) (ABNT, NBR 9050, 2015).

Essas formas de sinalização podem ser de quatro tipos: Permanente (Utilizada nas áreas e espaços cuja função já esteja definida); Direcional (Utilizada para indicar a direção de um percurso ou distribuição espacial dos diferentes elementos de um edifício); De emergência (Utilizada para indicar rotas de fuga e saídas de emergência ou para alertar quanto a um perigo eminente); Temporária 
(Utilizada para indicar informações provisórias ou que podem ser alteradas periodicamente) (ABNT, NBR 9050, 2015).

No que concerne a bibliotecas e centros de documentação adaptados para pessoas com deficiência visual especificamente, algumas das medidas relativas à sinalização mais relevantes que devem ser implementadas são a instalação de: Sinalização tátil interna - de localização em corrimãos e elevadores; de informação (para a identificação de acervo, das portas ou leitura de informativos dispostos pela biblioteca); Piso tátil ou podo tátil (Direcional e Alerta); Balcão de atendimento sinalizado; Terminal de atendimento preferencial; Mapa tátil da biblioteca.

A segunda questão teve a intensão de avaliar a frequência com que estes alunos utilizam os serviços da Seção Braille da Biblioteca Central. Cerca de $80 \%$ revelaram que nunca, e (20\%) que raramente frequentam a Seção Braille. Dentre as justificativas apresentadas, o U2 afirmou que:

"A distância e acesso, além do acervo não possuir materiais relacionados à minha área de estudos. Além disso, considero que o acervo está muito desatualizado."

A terceira questão relaciona-se ao acervo disponível na Seção Braille, se o discente considerase satisfeito, satisfeito em certos aspectos, indeciso, pouco satisfeito ou insatisfeito. O nível de satisfação entre os usuários, de um modo geral foi baixo, pelos mesmos fatores citados na questão de número 2 . De acordo com o U9:

\section{"O ponto forte da Seção é o vasto acervo infantil."}

A quarta questão concerne à acessibilidade da Seção Braille se o aluno considera-se satisfeito, satisfeito em certos aspectos, indeciso, pouco satisfeito ou insatisfeito, sendo possível justificar sua resposta. De acordo com o U3:

"Não me sinto satisfeito, pois considero que o acervo não supre mais as necessidades informacionais do público estudantil com deficiência visual da UFPB, além disso, o acervo não é higienizado."

Do total de respondentes, $80 \%$ dos participantes da pesquisa visitaram a Seção apenas uma vez durante todo seu curso. $\mathrm{O}$ acesso se dá através de escadas estreitas com degraus pequenos e piso bastante encerado, o que pode provocar risco de acidentes por ser escorregadio, conforme mostrado nas figuras $2,3,4$ e 5 . 
Figura 2- Acesso a Seção Braille

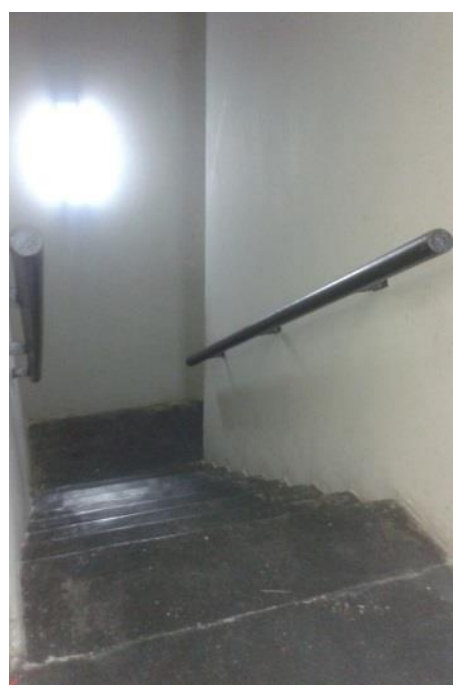

Fonte: Arquivo Pessoal, 2016
Figura 3- Piso escorregadio

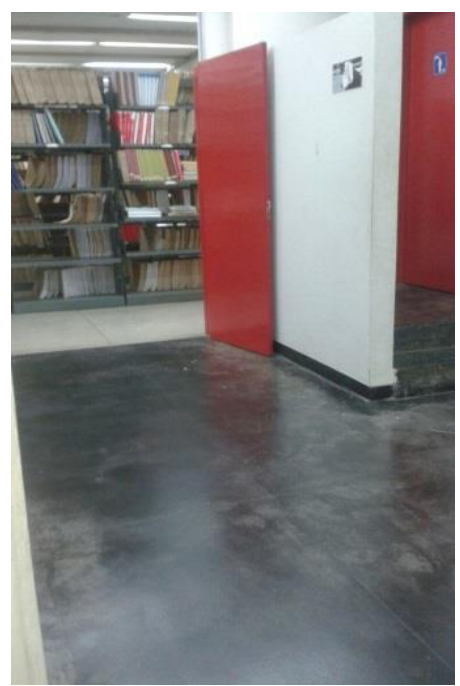

Fonte: Arquivo Pessoal, 2016.
Figura 4 - Mesas com pontas

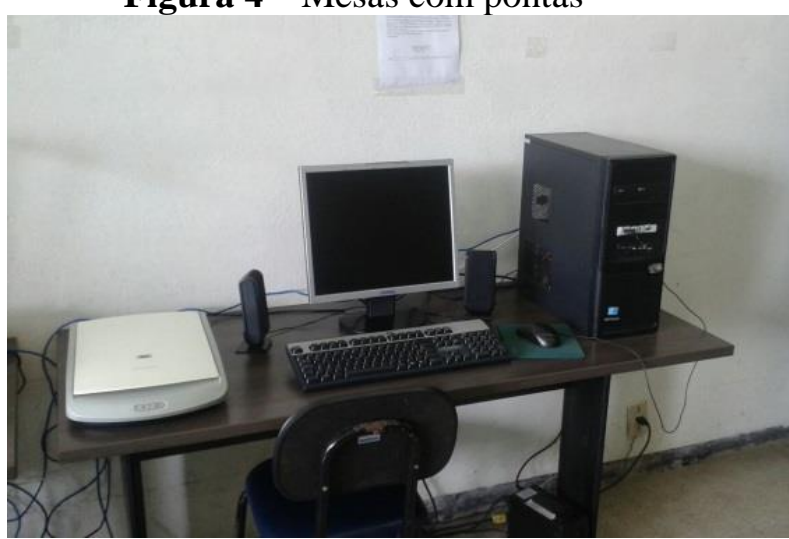

Fonte: Arquivo Pessoal, 2016.
Figura 5 - Acesso a Biblioteca Central

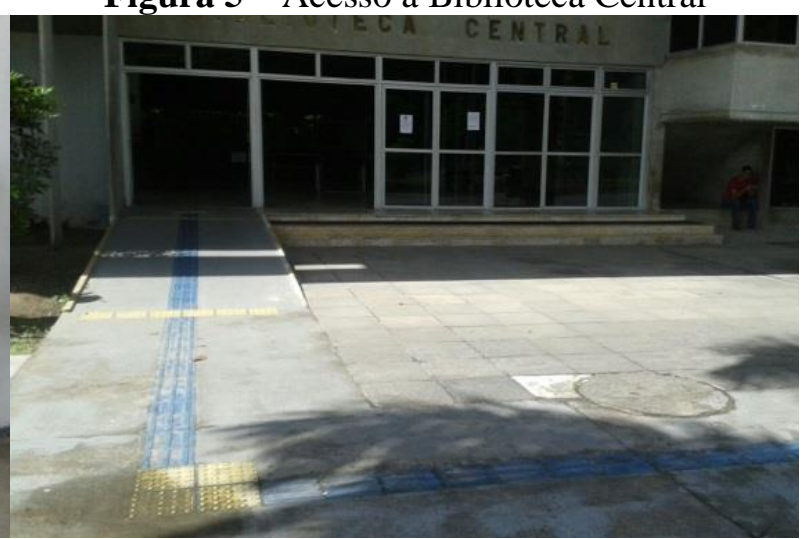

Fonte: Arquivo Pessoal, 2016.

De acordo com a ABNT NBR: 9050/2015, os corrimãos de escadas fixas e rampas devem ter sinalização tátil (caracteres em relevo e em Braille), identificando o pavimento. Essa sinalização deve ser instalada na geratriz superior do prolongamento horizontal do corrimão, conforme Figura 6. Na parede a sinalização deve ser visual e, opcionalmente, tátil, conforme Figura 6. Alternativamente, estas sinalizações podem ser instaladas nas paredes laterais. 
Figura 6 - Corrimão e Sinalização Tátil em Escadas
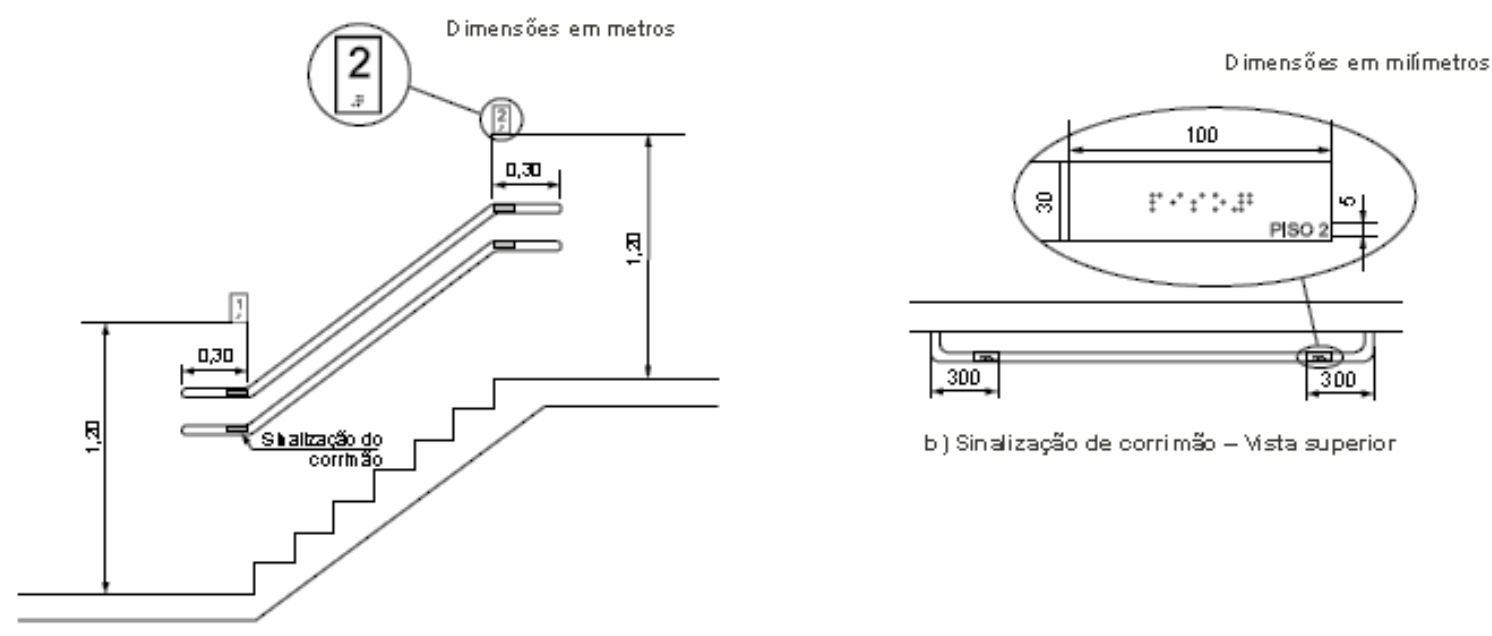

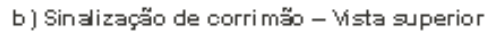

a) Sinaliz ação de pavi mento - Vista lateral

Fonte: ABNT NBR 9050, 2015.

A sinalização visual dos degraus de escada deve ser: a) aplicada aos pisos e espelhos em suas bordas laterais e/ou nas projeções dos corrimãos, contrastante com o piso adjacente, preferencialmente fotoluminescente ou retro iluminado, conforme as opções demonstradas na Figura 7; b) igual ou maior que a projeção dos corrimãos laterais, e com no mínimo $7 \mathrm{~cm}$ de comprimento e $3 \mathrm{~cm}$ de largura; c) fotoluminescente ou retro iluminada, quando se tratar de saídas de emergência e/ou rota de fuga (ABNT NBR 9050, 2015).

NOTA: Recomenda-se estender a sinalização no comprimento total dos degraus com elementos que incorporem também características antiderrapantes que auxiliaram também as pessoas com deficiência visual.

Figura 7 - Sinalização visual e tátil dos degraus da escada

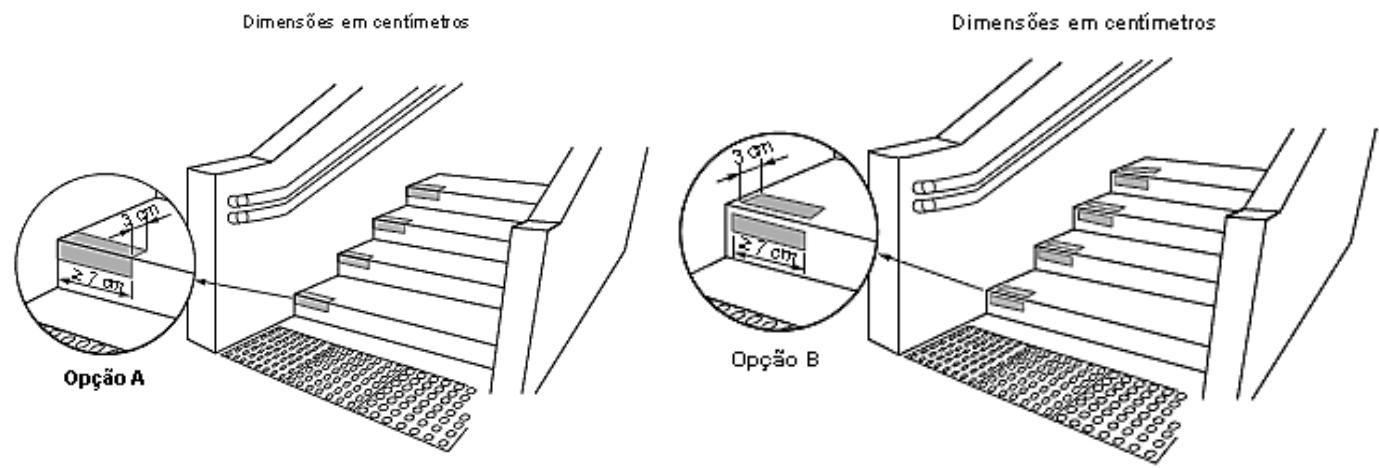

Fonte: ABNT NBR 9050, 2015.

A Figura 8 apresenta de acordo com a ABNT NBR: 9050/2015, dimensões referenciais para deslocamento das pessoas com deficiência visual em pé. 
Figura 8 - Deslocamento das pessoas com deficiência visual em pé
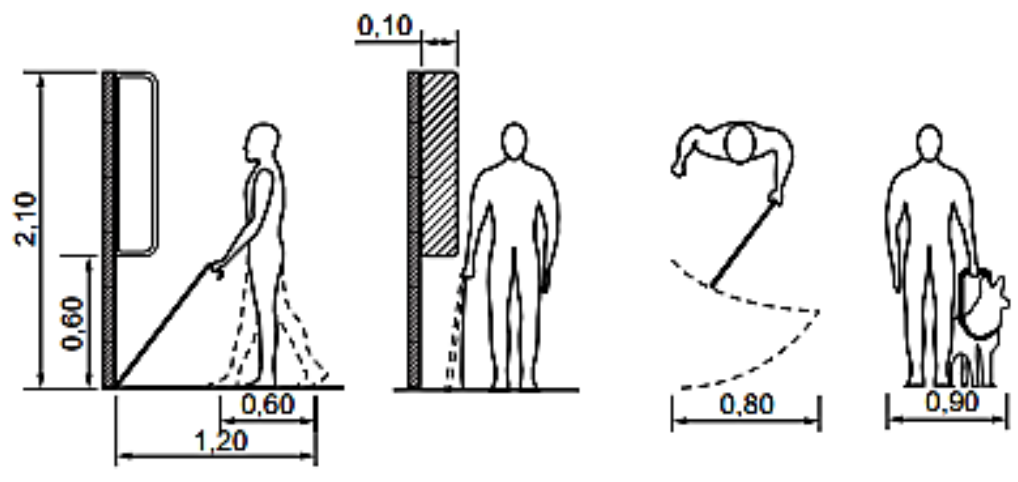

Bengala longa - Vistas lateral, frontal e superior Căo-guia

Fonte: ABNT NBR 9050, 2015.

Na quinta questão, foram listados alguns serviços existentes na Seção Braille, para que o aluno evidenciasse o que ele busca com mais frequência: o acervo, a impressão de livros em Braille, os áudio livros, o empréstimo de materiais ou os periódicos em Braille. Como os discentes pesquisados raramente utilizam a Seção, 50\% deles não sabiam de todos os serviços que a Seção dispõe, a exemplo dos áudiolivros.

A sexta questão relaciona-se ao grau de satisfação do usuário com relação aos serviços da Seção Braille, se o aluno considera-se satisfeito, satisfeito em certos aspectos, indeciso, pouco satisfeito ou insatisfeito, sendo possível justificar sua resposta. De acordo com o U5:

"Me sinto insatisfeito, pois a Seção poderia ser mais uma opção de completar as lacunas informacionais dos estudantes que possuem deficiência visual na UFPB".

O percentual de $70 \%$ dos pesquisados manifestaram que a melhoria deste serviço poderia inferir diretamente no aprendizado e desempenho deste público estudantil.

A sétima questão vislumbra identificar as barreiras informacionais identificadas por esses usuários. As principais barreiras citadas foram em relação à atualização e abrangência do acervo (90\%), sinalização (65\%) e a dificuldade de acesso a Seção Braille da Biblioteca Central da UFPB (100\%).

A oitava e última questão, coleta recomendações com o objetivo de melhorar a acessibilidade dos usuários deficientes visuais totais à Biblioteca Central da UFPB. A sugestão mais apontada pelos usuários relaciona-se a localização da Seção. De acordo com o U15:

“A Seção Braille deveria ser mais próxima dos Centros onde possuem mais alunos com deficiência visual, são eles: o Centro de Ciências Sociais Aplicadas (CCSA), o Centro de Educação (CE) e o Centro de Ciências Humanas, Letras e Artes (CCHLA) que abrangem os cursos das áreas de humanas, cursos que exigem muita leitura e materiais de pesquisa". 
Todos os respondentes fazem uso dos serviços do Núcleo de Educação Especial (NEDESP) que organiza, planeja, apoia, elabora e executa projetos na área de Educação Especial relativos à pesquisa e extensão, para docentes e discentes da UFPB, prestando atendimento psicopedagógico as pessoas com distúrbios do desenvolvimento e deficiências, localizado no Centro de Educação (CE).

\section{CONSIDERAÇÕES FINAIS}

Diante da importância de uma Seção que embasa estudantes com deficiência visual da Universidade Federal da Paraíba, esta pesquisa buscou conhecer quais as barreiras informacionais enfrentadas pelos usuários com deficiência visual total da Seção Braille da Biblioteca Central da Universidade Federal da Paraíba.

Para responder a questão proposta, foi traçado como objetivo geral e analisar as necessidades informacionais dos usuários com deficiência visual total da Seção Braille da Universidade Federal da Paraíba, discutido minuciosamente, além de cumprir os objetivos específicos de identificar as necessidades dos usuários da Seção Braille da Universidade Federal da Paraíba; descrever as barreiras informacionais que surgem aos usuários da Seção Braille da Universidade Federal da Paraíba e; apontar soluções para que essas barreiras sejam desarticuladas satisfazendo o usuário da Seção Braille da Universidade Federal da Paraíba. Quanto à acessibilidade, percebeu-se que a Biblioteca Central e a Seção Braille da UFPB não possuem atualmente uma proposta estruturada de serviços que atendam a demanda atual da Universidade. Sugere-se, desse modo, a preparação para as demandas futuras de estudantes com deficiência visual.

O rompimento das barreiras em torno da acessibilidade é primordial para permitir que essas pessoas sejam incluídas na Sociedade da Informação, pois não se deve pensar apenas nas mudanças física da biblioteca. É preciso ir além: desenvolver uma conscientização por parte das pessoas que trabalham nas unidades de informações, uma forma de pensar mais inclusiva, deixando isso refletir em suas atitudes.

É de suma importância que se adotem essas medidas de sinalização, prescritas na NBR 9050 da $\mathrm{ABNT}$, visto que garantem a segurança das pessoas com deficiência visual dentro da biblioteca, facilitando a sua locomoção pelo ambiente e dotando-as de maior autonomia. Como sugestão para as próximas pesquisas, fica evidente a importância do um estudo de Marketing acerca da seção Braille. Acredita-se que o problema destacado por este trabalho da pouca frequência dos usuários na Seção pode ser resolvido a partir de projetos que melhorem a perspectiva do marketing no espaço.

\section{REFERÊNCIAS}

AQUINO, Mirian de Albuquerque. O campo da ciência da informação: gênese, conexões e especificidade. João Pessoa: Editora Universitária, 2002.

ASSOCIAÇÃO BRASILEIRA DE NORMAS TÉCNICAS. NBR 9050: Acessibilidade a edificações, mobiliário, espaços e equipamentos urbanos. Rio de Janeiro, 2015. 
BERNHEIM, C. T.; CHAUI, M. Desafios da universidade na sociedade do conhecimento. Brasília: Unesco, 2008.

BEZERRA, Emy Porto. Digitalizando o Virtual: uma análise Informacional do Processo de Implementação da Biblioteca Digital Paulo Freire. João Pessoa: 2003. Disponível:

$<$ http://enancib.ibict.br/index.php/enancib/xenancib/paper/viewFile/3374/2500>. Acesso em: 06 abr. 2019.

BRASIL. RESOLUÇÃO No 31/2009, 26 de maio de 2009. Aprova o Regimento Interno do Sistema de Biblioteca da UFPB. João Pessoa, 2009.

CERVO, Amado Luiz; SILVA, Roberto Da; BERVIAN, Pedro A. Metodologia científica. 6.ed. São Paulo: Pearson Education, 2007.

CHAUÍ, M. A universidade pública sob nova perspectiva. In: Conferência de abertura da $\mathbf{2 6}^{\mathbf{a}}$ reunião anual da ANPED, Poços de Caldas, 5 de outubro de 2003.

FERREIRA, Lusimar Silva. Bibliotecas universitárias brasileiras: análise de estruturas centralizadas e descentralizadas. São Paulo: Pioneira, 1980.

FREIRE, Isa Maria. Barreiras na comunicação da informação tecnológica. Ci. Inf., Brasília, v.20, n.1, p.51-54, jan./jun. 1991.

GERHARD, Tatiana Engel. et al. Métodos de pesquisa. Porto Alegre: Editora da UFRGS, 2009.

GIL, A. C. Como elaborar projetos de pesquisa. São Paulo: Atlas, 2007.

GUINCHAT, C.; MENOU, M. Introdução geral às ciências e técnicas da informação e documentação. 2.ed. rev. aum. Brasília: IBICT; CNPq, 1994. 540 p.

LE COADIC, Yves-François. A Ciência da informação. Tradução de Maria Yêda F. S. de Figueiras Gomes. 2.ed. Brasília, Briquet de Lemos, 2004.

MALHEIROS, T. M. de C. Estudo do usuário deficiente visual e subsídios para uma política de desenvolvimento de coleções da Biblioteca Central da Universidade de Brasília. 2009. 94f. Monografia (Especialização em Gestão Universitária) - Universidade de Brasília, Brasília, 2009.

MARCONI, Marina de Andrade; LAKATOS, Eva Maria. Metodologia científica. 6. ed. São Paulo: Atlas, 2011.

MARQUES, C.A.; MARQUES, L.P. Do universal ao múltiplo: os caminhos da inclusão. In: LISITA, V. e SOUSA, L. (Org.) Práticas educacionais, práticas escolares e alternativas de inclusão escolar. Rio de Janeiro: DPA, 2003.

MORAES, Cláudio. Usuários de bibliotecas: informação X cidadão comum. Biblios, Rio Grande, v. 6, p.119-133, 1994.

OLIVEIRA, Marlene de. et al. Ciência da informação e biblioteconomia: novos conteúdos e espaços de atuação. Belo Horizonte: Editora UFMG, 2005.

PINHO NETO, J.A.S. A Inclusão Digital para Deficientes Visuais do Setor Braille da Biblioteca Central da UFPB. Pesq. Bras. em Ci. da Inf. e Bib.,João Pessoa, v.8, n. 2, p. 001-009, 2013.

Disponível em: < http://periodicos.ufpb.br/index.php/pbcib/article/viewFile/18135/10442>. Acesso em: 06 abr. 2019. 
PUPO, D.T; BONILHA, F.F.G.; CARVALHO, S.H.R. Laboratório de Acessibilidade: criação, implantação e atendimento a usuários com necessidades especiais, na Biblioteca Central da Unicamp. In: SEMINÁRIO NACIONAL DE BIBLIOTECAS UNIVERSITÁRIAS, SNBU,13, Natal-RN, 17-21 de outubro de 2004. Anais... cd-rom.

PUPO, D. T.; MELO, A. M.; FERRES, S. P. Acessibilidade: discurso e prática no cotidiano das bibliotecas. Campinas: Unicanp, 2008. 137p.

SILVA, E. S. da et al. Redimensionamento do serviço de automação das bibliotecas da UFPB. In: SEMINARIO NACIONAL DE BIBLIOTECAS UNIVERSITARIAS, 13; 2004, Natal. Anais... Natal: Universidade Federal do Rio Grande do Norte: BCZM, 2004. 12p. ISBN 85- 88183-02-1.

STAREC, Claudio. A Gestão estratégica da informação na universidade: os pecados informacionais e barreiras na comunicação da informação para a tomada de decisão na Universidade Estácio de Sá. 2006. Disponível em: < http://www.brapci.inf.br/index.php/article/download/7486>. Acesso em: 06 abr. 2019.

SOUZA, M. A. L. Biblioteca pública inclusiva: adaptar para renovar. CRB-8 Digital, São Paulo, v. 6 , n. 1, p. 33-41, ago. 2013. 